Original Article (short paper)

\title{
Do athletes with physical disabilities perceive their quality of life similarly when involved in different Paralympic Sports?
}

\author{
Vitor Ciampolini ${ }^{1}$ (อ, Marília Garcia Pinto ${ }^{1}$, Gabriel Renaldo de Sousa ${ }^{1}$ (1), \\ Diego Augusto Santos Silva ${ }^{1}$, , Larissa Rafaela Galatti² ${ }^{(1)}$ \\ ${ }^{1}$ Universidade Federal de Santa Catarina, UFSC, Graduate Program in Physical Education, Florianópolis, SC, Brazil;
${ }^{2}$ Universidade Estadual de Campinas, UNICAMP, Faculdade de Ciências Aplicadas, FCA, Limeira, SP, Brazil
}

\begin{abstract}
Aim: This study aimed to compare the quality of life perception among Boccia, Para-Athletics, and Wheelchair Tennis athletes. Methods: Eighty-six athletes with physical disabilities participated $($ Boccia $=41$; Para Athletics $=14$; Wheelchair Tennis = 31) in the study. The data were collected by applying the Brazilian Portuguese version of the WHOQOLBref questionnaire and a short survey for demographics. Descriptive and inferential statistics were used to analyze the relationship among the variables considering a confidence level of $95 \%$. Results: Wheelchair Tennis athletes were older and Para-Athletics athletes were involved in this sport for a longer period. The majority of participants perceived positively their overall quality of life and health. Wheelchair Tennis athletes presented higher total quality of life perception scores in comparison to Boccia athletes. Regarding the specific domains of quality of life, Para-Athletics athletes presented higher scores in the psychological domain in comparison to Boccia and Wheelchair Tennis. Wheelchair Tennis presented higher social scores in comparison to Boccia and higher environment scores in comparison to Boccia and Para-Athletics. No differences were found in the physical domain in all groups. Conclusion: The evidence points to the influence of athletes' demographics, the specific nuances of their impairments, and the Paralympic Sports practiced in perceiving the quality of life. Suggestions are made to further explore the factors that may influence the quality of life perception among Paralympic Sports athletes.
\end{abstract}

Keywords: adapted sports; health; people with disabilities; impairment.

\section{Introduction}

The promotion of adapted physical activities for people with disabilities is a largely investigated ${ }^{1,2}$. Among the various possibilities of such activities, adapted sports has been shown to be an effective alternative, considering the social, physical, and psychological contributions usually reported by the participants $s^{3,4}$. These benefits have been manifested through the enhancement of functional capacity, development of relationships, and increased self-esteem ${ }^{5,6}$. In addition, adapted sports was pointed out in the scientific literature due to the contribution for a positive quality of life (QoL) perception among athletes with physical disabilities ${ }^{4,6,7}$.

Recent investigations on the QoL, people with physical disabilities who are regularly involved in adapted sports pointed out to the better perception of these individuals in comparison to their inactive peers ${ }^{4,8}$. When investigating the factors that contribute to a higher QoL perception, a higher number of training session per week ${ }^{9}$, a longer period practicing an adapted sport ${ }^{7}$, and involvement in the high-performance contex $\mathrm{t}^{10}$ were highlighted. However, it is important to note that, until now, the analysis of factors influencing QoL perception among athletes with disabilities were performed considering individuals of only one sport ${ }^{9,10}$ or through grouping different sports into a large sample group ${ }^{7}$. Thus, there is a need to investigate athletes with physical disabilities' QoL perception considering the specific features and the common disabilities covered by each adapted sport.
Although the list of adapted sports is vast as a result of including any type of sports modified or created to meet the needs of people with disabilities ${ }^{11}$, Paralympic Sports are the group of 22 adapted sports that are part of the Summer Paralympic Games and the six adapted sports competed in the Winter Paralympic Games $^{11}$. Unlike adapted sports, Paralympic Sports comprise physical, visual, and intellectual disabilities ${ }^{12}$. In addition, to legitimately participate in these sports, the individual must present at least one of the ten eligibility criteria (eight for physical disability, one for visual disability, and one for intellectual disability) indicated by the International Paralympic Committee ${ }^{12}$.

Considering that the three types of disabilities aforementioned require different adaptations in ones' life, we hypothesized that the specific characteristics of each type of disability may influence the QoL perception, considering the physical, psychological, social, and environment domains ${ }^{13}$. Thus, the innovation in this study is settled in analyzing athletes with physical disabilities' QoL perception according to the nuances of their disability and the sport they practice. The comparison across different adapted sports can provide important directions about the barriers of each context and how sports stakeholders and coaches can create a climate for promoting better levels of QoL. In order to cover athletes that exhibit different types of disabilities and participate in different sporting environments, we chose Boccia, Para-Athletics (PA), and Wheelchair Tennis (WT). Therefore, considering the rationale aforementioned, this study aimed to compare the QoL perception among Boccia, PA, and WT athletes. 


\section{Methods}

This is a cross-sectional study from a quantitative approach. This research was approved by the Ethics Committee of the lead author's university (protocol No. 717.655) and all participants agreed to participate in the study.

\section{Participants}

Participants were athletes with physical disabilities practicing Boccia, PA, or WT. Sampling was intentionally performed and counted on athletes participating in regional, national, or international tournaments visited by the researchers. As inclusion criteria, athletes should be over 18 years of age, have Brazilian nationality, exhibit a physical disability, sign an informed consent and fill in the questionnaires in a way that would not generate doubts to researchers. Thus, the sample consisted of 41 Boccia athletes, $14 \mathrm{PA}$ athletes, and $31 \mathrm{WT}$ athletes, totaling 86 subjects.

\section{Participants'Sports' Characteristics}

Boccia only includes athletes with physical disabilities and comprises six of the eight criteria for eligibility ${ }^{12}$. Its main characteristic is the opportunity for people with a severe degree of motor impairment to participate in a sporting activity, who would otherwise have little chances of being involved in such environment ${ }^{14}$. The disabilities normally exhibited by Boccia athletes are cerebral palsy, progressive muscular dystrophy, and stroke ${ }^{14}$.

PA is the only one in this study to comprise all three types of disabilities in the Paralympic program ${ }^{15}$. Taking into account that all eligibility criteria are covered in PA and the 23 classes for track events and 26 classes for field events offered ${ }^{12}$, different implements are used for competing, such as: throwing the chair, race guide, wheelchair, or prostheses ${ }^{12}$.

WT comprises all eight eligibility criteria related to physical disability, not covering intellectual and visual disabilities ${ }^{12,16}$. There are two categories for participating in the events: open and quad $^{12}$. The open category is aimed at individuals with significant and permanent disabilities in at least one lower limb without compromising upper limb function. The quad category includes people with disabilities affecting arms and legs, which make it difficult to grip the racket and move on the court ${ }^{12}$.

It is important to understand that due to the fact that the three Paralympic Sports cover individuals with different functional abilities, it is difficult to indicate which athletes present greater motor impairment. However, considering the characteristics of these activities and the athletes that normally participate in the competitions, the disabilities exhibited by Boccia athletes provide higher motor impairment, followed by WT, and PA.

\section{Instruments}

The Portuguese version of the WHOQOL-Bref instrument (World Health Organization Quality of Life - Bref) proposed by
Fleck et al. ${ }^{13}$ was used. The WHOQOL-Bref contains 26 questions and evaluates the subject's perceived QoL through a five-point likert scale ${ }^{13}$. The first two questions investigate, in general, how individuals evaluate their QoL and how satisfied they are with their health, respectively ${ }^{17}$. The following 24 questions are divided into four domains: physical (seven questions), psychological (six questions), social (three questions), and environment (eight questions). Regarding the instrument validation, the study conducted by Fleck et al. ${ }^{13}$ identified reliability coefficients of 0.69 or higher (physical $=0.84$, psychological $=0.79$, social $=$ 0.69 , environment $=0.71$ ).

In addition to the application of the instrument, a brief questionnaire was given to the athletes to collect information regarding age, sex, the cause of disability, and average years practicing their respective sport.

\section{Data Collection}

Data were collected through visits of the researchers at practices or tournaments of each sport.

- Boccia: In November 2014, researchers visited a round of the Brazilian Boccia Championship for individual categories. Athletes answered the questionnaires on the day off the competition.

- PA: The event selected for researchers' visit took place in November 2015 during a round of the Brazilian PA Circuit. Questionnaires were given to athletes during the day off the competition.

- WT: Athletes were contacted in two moments: (1) in May 2014, six national level athletes were surveyed at the end of a practice session; (2) in October 2014, twenty-five participants of an international WT championship held in southern Brazil answered to the questionnaires.

\section{Data analysis}

The analysis of participants' responses usually follows procedures suggested by WHOQOL Group ${ }^{17}$. In this way, questions one and two of the instrument had a particular interpretation. For question one "How would you rate your quality of life?", subjects were classified as negative evaluation when they answered 'very poor', 'poor' or 'neither poor nor good', and as a positive evaluation those who answered 'good' or 'very good'. For question two "How satisfied are you with your health?", participants who answered 'very dissatisfied', 'dissatisfied' or 'neither satisfied nor dissatisfied' were classified as negative evaluation and those who answered 'satisfied' or 'very satisfied' were classified as positive evaluation.

For analyzing data, descriptive statistics with mean, standard deviation, and absolute and relative frequency values were used. To verify the data normality of the quantitative variables, Shapiro-Wilk and Kolmogorov-Smirnov tests were applied. When the data normality was identified, one-way ANOVA test for independent samples was applied, followed by a Bonferroni 
post hoc or the non-parametric equivalent (Kruskal-Wallis test). In order to identify an association between categorical variables, Fisher's exact and chi-square tests were adopted. In all analyses, a confidence level of $95 \%$ was considered and the tests were carried out using SPSS software (version 23.0).

\section{Results}

The eight-six participants (women $=27$, men $=59$ ) had age ranging from 18 to 65 years and had congenital $(n=33)$ or acquired physical disability $(n=49)$. Four individuals opted not to indicate the cause of their disability. When participants were stratified according to the sports practiced, WT athletes had the highest mean age among participants $(39.35 \pm 11.57)$, followed by PA (32.50 \pm 10.37$)$ and Boccia athletes (31.76 \pm 9.36$)$, respectively. Regarding the average years practicing their respective sport, the highest mean was PA $(10.03 \pm 7.76)$, followed by WT $(7.78 \pm 5.80)$, and Boccia $(6.42 \pm 4.54)$, according to Table 1.

The general evaluation of QoL and general health satisfaction levels of Boccia, PA, and WT athletes did not present significant difference, as presented in Tables 2 and 3.

Regarding the QoL perception across Paralympic Sports, WT presented the highest total perception score, which was significantly higher than Boccia. Regarding the domain-specific analysis, physical domain did not present a significant difference among the other sports. In the psychological domain, PA had a higher mean in relation to Boccia and to WT $(\mathrm{p}<0.05)$. In the social domain, WT had a higher average than the other sports, especially in relation to Boccia $(\mathrm{p}<0.05)$. Finally, regarding the environment domain, a higher mean of WT was identified when compared to PA and Boccia $(\mathrm{p}<0.05)$. The scores for each domain can be found in Table 4.

Table 1. Characterization of the research participants.

\begin{tabular}{|c|c|c|c|c|c|c|}
\hline \multirow{3}{*}{ Paralympic Sport } & \multirow{2}{*}{ Age } & \multicolumn{2}{|c|}{ Sex } & \multicolumn{2}{|c|}{ Disability } & \multirow{2}{*}{$\begin{array}{l}\text { Average years practicing } \\
\text { their respective sport }\end{array}$} \\
\hline & & Female & Male & Congenital & Acquired & \\
\hline & Mean \pm SD & \multicolumn{2}{|c|}{ n (\%) } & \multicolumn{2}{|c|}{ n (\%) } & Mean \pm SD \\
\hline Boccia & $31.76 \pm 9.36$ & $15(36.6)$ & $26(63.4)$ & $23(62.2)$ & $14(37.8)$ & $6.42 \pm 4.54$ \\
\hline PA & $32.50 \pm 10.37$ & $6(42.9)$ & $8(57.1)$ & $7(50.0)$ & $7(50.0)$ & $10.03 \pm 7.76$ \\
\hline WT & $39.20 \pm 11.57$ & $6(19.4)$ & $25(80.6)$ & $3(9.7)$ & $28(90.3)$ & $7.78 \pm 5.80$ \\
\hline Total & $34.62 \pm 10.85$ & $27(31.4)$ & $59(68.6)$ & $33(40.2)$ & $49(59.8)$ & $7.52 \pm 5.71$ \\
\hline
\end{tabular}

Note. PA: Para Athletics; WT: Wheelchair Tennis; SD: Standard Deviation.

Table 2. Overall QoL assessment among Paralympic Sport athletes.

\begin{tabular}{|c|c|c|c|c|c|}
\hline \multirow{2}{*}{ Paralympic Sport } & & \multicolumn{2}{|c|}{ Overall QoL assessment } & \multirow{2}{*}{ Total } & \multirow{2}{*}{ p-value } \\
\hline & & Negative & Positive & & \\
\hline \multirow{2}{*}{ Boccia } & $\mathrm{n}$ & 4 & 37 & 41 & \multirow{8}{*}{$0.875^{\mathrm{a}}$} \\
\hline & $\%$ & 9.8 & 90.2 & 100.0 & \\
\hline \multirow{2}{*}{ PA } & $\mathrm{n}$ & 1 & 13 & 14 & \\
\hline & $\%$ & 7.1 & 92.9 & 100.0 & \\
\hline \multirow{2}{*}{ WT } & $\mathrm{n}$ & 2 & 29 & 31 & \\
\hline & $\%$ & 6.5 & 93.5 & 100.0 & \\
\hline \multirow{2}{*}{ Total } & $\mathrm{n}$ & 7 & 79 & 86 & \\
\hline & $\%$ & 8.1 & 91.9 & 100.0 & \\
\hline
\end{tabular}

Note. ${ }^{\text {a: }}$ Fisher's Exact Test; PA: Para Athletics; WT: Wheelchair Tennis.

Table 3. Overall satisfaction with health among Paralympic Sport athletes.

\begin{tabular}{|c|c|c|c|c|c|}
\hline \multirow{2}{*}{ Paralympic Sport } & & \multicolumn{2}{|c|}{ Overall satisfaction with health } & \multirow{2}{*}{ Total } & \multirow{2}{*}{ p-value } \\
\hline & & Unsatisfied & Satisfied & & \\
\hline \multirow{2}{*}{ Boccia } & $\mathrm{n}$ & 8 & 33 & 41 & \multirow{8}{*}{$0.744^{b}$} \\
\hline & $\%$ & 19.5 & 80.5 & 100.0 & \\
\hline \multirow{2}{*}{ PA } & $\mathrm{n}$ & 4 & 10 & 14 & \\
\hline & $\%$ & 28.6 & 71.4 & 100.0 & \\
\hline \multirow{2}{*}{ WT } & $\mathrm{n}$ & 8 & 23 & 31 & \\
\hline & $\%$ & 25.8 & 74.2 & 100.0 & \\
\hline \multirow{2}{*}{ Total } & $\mathrm{n}$ & 20 & 66 & 86 & \\
\hline & $\%$ & 23.3 & 76.7 & 100.0 & \\
\hline
\end{tabular}

Note. ${ }^{\text {b: }}$ Chi-square test; PA: Para Athletics; WT: Wheelchair Tennis. 
Ciampolini V. \& Pinto M. G. \& Sousa G. R.\& Silva D. A. S. \& Galatti L. R.

Table 4. Perception reported according to the Paralympic Sport practiced and the domains of QoL.

\begin{tabular}{ccccc}
\hline & \multicolumn{3}{c}{ Paralympic Sport } & WT \\
\cline { 2 - 4 } Domains & Boccia & PA & Mean \pm SD & \\
\cline { 2 - 4 } & Mean \pm SD & $73.49 \pm 14.02$ & $70.32 \pm 6.63$ & $0.544 \dagger$ \\
\hline Physical & $70.94 \pm 9.92$ & $82.04 \pm 10.80$ & $77.42 \pm 6.13$ & $0.047 ¥$ \\
Psychological $^{1,2}$ & $76.34 \pm 11.78$ & $80.00 \pm 14.28$ & $83.44 \pm 10.87$ & $0.028 ¥$ \\
Social $^{3}$ & $75.93 \pm 12.19$ & $71.94 \pm 8.38$ & $76.93 \pm 10.64$ & $<0.001 \dagger$ \\
Environment $^{1,3}$ & $64.88 \pm 9.03$ & $76.87 \pm 10.09$ & $77.03 \pm 6.30$ & $0.024 \dagger$ \\
Total $^{3}$ & $72.02 \pm 8.96$ & & & Mean \pm SD \\
\hline
\end{tabular}

Note. PA: Para Athletics; WT: Wheelchair Tennis; SD: Standard Deviation.

$\uparrow$ One-Way ANOVA; $¥$ Kruskal-Wallis test; ${ }^{1}$ - Significant difference between PA and WT;

2 - Significant difference between PA and Boccia; ${ }^{3}$ - Significant difference between WT and Boccia.

\section{Discussion}

The main objective of this study was to compare the QoL perception among Boccia, PA, and WT athletes. From the analysis of the overall QoL perception and health, we identified that athletes perceive positively both of the indicators. This finding corroborates other studies regarding the importance of adapted sports to the promotion of QoL and health for this population ${ }^{4,5,10}$. In addition, regardless of the Paralympic Sport practiced and the public covered (athletes with more severe or less severe impairments), participation in adapted sports by itself seemed to have supported athletes with physical disabilities to positively perceive their QoL and health. Thus, although physical disability is sometimes a limiting factor for autonomy and accessibility ${ }^{2}$, this seems not to be a primordial aspect when performing an overall assessment of QoL and health.

Regarding total QoL perception, WT athletes presented significantly higher mean in comparison to Boccia athletes. It is believed that this fact can be explained by the higher average age of WT athletes compared to Boccia athletes, since there is a tendency of greater acceptance of the disability over time, resulting in less embarrassing situations in relation to difficulties in activities of the daily living ${ }^{18}$. Further, given that Boccia athletes generally have a higher degree of severity and motor impairment than WT athletes, this fact may have negatively influenced their QoL perceptions. In order to help support maintaining athletes in Paralympic Sports, attention should be given to young athletes with higher degrees of motor impairment, considering the presence of two factors that may interfere in high levels of QoL perception.

Among WHOQOL-Bref domains, the physical domain was the only one that did not show significant difference between at least two of the sports investigated and all the scores in this domain were lower than those observed in the psychological and social domains. It should be noted that the physical domain seeks to measure an individual's perception of pain, medical treatment, disposition, mobility, sleep quality, daily activities, and work capacity ${ }^{13}$. Although Boccia includes individuals with greater motor impairment, evidence indicates that Boccia athletes' perception on the physical domain is similar to those of PA and WT. Thus, it is believed that the physical contributions resulting from the individual's participation in Paralympic Sports ${ }^{5,19}$ contribute in a similar way to the QoL perception in this domain, regardless of sport practiced.

Regarding the psychological domain, which aims to verify aspects related to self-esteem, body image, spirituality, and negative and positive feelings ${ }^{13}$, we identified that PA athletes had higher scores than Boccia and WT athletes. Therefore, we suggest that even though the sports is an important tool for the improvement and maintenance of $\mathrm{QoL}^{4,20}$, individuals who exhibit more severe impairments and may need caregivers and special attention tend to have lower perception scores in the psychological domain.

In the social domain, it was observed that WT athletes obtained higher average scores in relation to Boccia athletes. One aspect that may have contributed to the lower average scores presented by Boccia athletes may be the characteristics of the disabilities exhibited by athletes of this sport, which may hinder social interaction and integration. Indeed, the disabilities normally exhibited by athletes of this sport ${ }^{14}$ may negatively affect communication skills and, in certain cases, may require alternative strategies to facilitate $i^{21}$.

Regarding the environment domain, WT athletes had higher values compared to PA and Boccia athletes. It is believed that because WT athletes also had higher mean age among the sports investigated, there is a tendency for these individuals to be in more advanced stages of their professional career and, consequently, they are more financially stable. Considering the difficulties of accessibility and mobility in Brazil ${ }^{22,23}$, owning a car, living in an accessible neighborhood and at an adapted house are aspects that can contribute to a positive QoL perception. In addition, the characteristics of disabilities usually exhibited by Boccia athletes may be barriers to inclusion in the labor market ${ }^{24}$ and, consequently, to facilitate access to the aforementioned aspects.

Finally, it is important to highlight the factor 'average years practicing their respective sport' in the QoL perception of people with physical disabilities. Despite not having specified the difference between sports, Laferrier, Teodorski, Cooper ${ }^{7}$ identified the influence of this factor on military veterans with disabilities from the United States Army. Overall, the results of this study are consistent with this finding, since athletes of sports that presented the longest time practicing it (i.e. PA and WT) also had higher total QoL perception. 
However, this study has important limitations that should be reported. The first one is the convenience sample, which does not guarantee that the characteristics presented by athletes of this study are similar to athletes from around the country and the world. The second limitation is the lack of stratification of functional classes inherent to the Paralympic Sports investigated. The third limitation is the cross-sectional design, which did not allow the identification of individuals' QoL perception before starting to practice a sport and, consequently, a followup throughout the period of involvement.

\section{Conclusion}

The results of this study allow us concluding that athletes with physical disabilities' demographics, the specific nuances of their impairments, and the characteristics of the Paralympic Sport practiced are aspects that influence their QoL perception; especially in a general perception along with psychological, physical, and environment domains. These results allow directing the attention to the competitive and recreational environments to meet the needs of each sport, facilitate the inclusion of athletes with physical disability, and promote better levels of QoL perception. In addition, the importance of developing public policies and greater attention to individuals with greater motor impairment is emphasized, since Boccia athletes presented the lowest scores in the psychological, social, and environment domains. However, despite the lower QoL scores identified, most participants showcased a positive perception of QoL and health.

\section{References}

1. Barak S, Hutzler Y, Dubnov-Raz G. Physical exercise for people with cerebral palsy: effects, recommendations and barriers. Harefuah. 2014;153(5):266-72.

2. Jaarsma EA, Dijkstra PU, Geertzen JHB, Dekker R. Barriers to and facilitators of sports participation for people with physical disabilities: A systematic review. Scand J Med Sci Sports. 2014;24(6):871-81.

3. Blauwet C, Willick SE. The Paralympic Movement: using sports to promote health, disability rights, and social integration for athletes with disabilities. PM \& R. 2012;4(11):851-6.

4. Yazicioglu K, Yavuz F, Goktepe AS, Tan AK. Influence of adapted sports on quality of life and life satisfaction in sport participants and non-sport participants with physical disabilities. Disabil Health J. 2012;5(4):249-53.

5. Wilhite B, Shank J. In praise of sport: promoting sport participation as a mechanism of health among persons with a disability. Disabil Health J. 2009;2(3):116-27.

6. Pereira R, Osborne R, Pereira A, Cabral SI. A importância do desporto de alto rendimento na inclusão social dos cegos: Um estudo centrado no Instituto Benjamin Constant - Brasil [The importance of high performance sports in social inclusion of blind people: A study centered on Benjamin Constant Institute - Brazil]. Motricidade. 2013;9(2):94-105.

7. Laferrier JZ, Teodorski E, Cooper RA. Investigation of the impact of sports, exercise, and recreation participation on psychosocial outcomes in a population of veterans with disabilities: A cross-sectional study. Am J Phys Med Rehabil. 2015;94(12):1026-34.

8. Anneken V, Hanssen-Doose A, Hirschfeld S, Scheuer T, Thietje R. Influence of physical exercise on quality of life in individuals with spinal cord injury. Spinal Cord. 2010;48(5):393-9.

9. Chatzilelecas E, Filipovic B, Petrinovic L. Differences in quality of life according to the level of physical activity between two groups of basketball players in the wheelchairs. SportLogia. 2015;11(1):11-7.

10. Ciampolini V, Columna L, Lapolli B, Iha T, Carter Grosso E, Silva DAS, et al. Quality of life of Brazilian wheelchair tennis athletes across competitive and elite levels. Motriz: J Phys Ed. 2017;23(2):1-6.

11. Winnick JP, Porretta DL, editors. Adapted Physical Education and Sport. 6 ed. Champaign, IL: Human Kinetics; 2017.

12. IPC. Explanatory guide to Paralympic classification. Bonn, Germany 2015 [cited 27 mar 2018]. Available from: http://m.paralympic.org/ sites/default/files/document/150915170806821_2015_09_15+Explanatory+guide+Classification_summer+FINAL+.pdf.

13. Fleck MP, Louzada S, Xavier M, Chachamovich E, Vieira G, Santos $\mathrm{L}$, et al. Aplicação da versão em português do instrumento abreviado de avaliação da qualidade de vida" WHOQOL-bref" [Application of the Portuguese version of the abbreviated instrument of quality life WHOQOL-bref]. Rev Saúde Pública. 2000;34(2):178-83.

14. Vieira IB, Campeão M. Bocha [Boccia]. In: Mello MT, Winckler C, editors. Esporte Paralímpico. São Paulo, Editora Atheneu; 2012. p. 83-91.

15. IPC. Athletics: International Paralympic Committee; 2018 [Cited 27 mar 2018]. Available from: https://www.paralympic.org/athletics/ about.

16. ITF. Regulations for wheelchair tennis 2018. London, UK: ITF LTD; 2018 [cited 27 mar 2018]. Available from: http://www.itftennis. com/media/278520/278520.pdf.

17. WHOQOL GROUP. Development of the World Health Organization WHOQOL-Bref quality of life assessment. Psychol Med. 1998;28(3):551-8.

18. Resende MD, Neri AL. Atitudes de adultos com deficiência física frente ao idoso, à velhice pessoal e a pessoas com deficiência física [Physically disabled adults's attitudes toward elderly people, personal old age, and other physically disabled persons]. Estud Psicol. 2005;22(2):123-31.

19. Webborn N, Van de Vliet P. Paralympic medicine. Lancet. 2012;380(9836):65-71.

20. Côté-Leclerc F, Duchesne GB, Bolduc P, Gélinas-Lafrenière A, Santerre C, Desrosiers J, et al. How does playing adapted sports affect quality of life of people with mobility limitations? Results from a mixed-method sequential explanatory study. Health Qual Life Outcomes. 2017;15(1):22.

21. Baltor MRR, Borges AA, Dupas G. Interação com a criança com paralisia cerebral: comunicação e estigma [Interaction with children with cerebral palsy: Communication and stigma]. Esc Anna Nery. 2014; 18(1):47-53.

22. Lamônica DAC, Araújo-Filho P, Simomelli SBJ, Caetano VLSB, Regina MRR, Regiani DM. Acessibilidade em ambiente universitário: identificação de barreiras arquitetônicas no campus da USP de Bauru [Accessibility in the university environment: Identification of architectural barriers in the USP campsus of Bauru]. Rev Bras Educ Espec. 2008;14(2):177-88. 
23. Castro SS, Lefèvre F, Lefèvre AMC, Cesar CLG. Acessibilidade aos serviços de saúde por pessoas com deficiência [Accessibility to health services by persons with disabilities]. Rev Saúde Pública. 2010;45(1):99-105.

24. Kennedy RB, Harris NK. Employing persons with severe disabilities: Much work remains to be done. J Employ Couns. 2005;42(3):133-9.

\section{Acknowledgments}

We would like to thank Professor Karla Costa de Liz for her deep contribution in collecting data for this study. Also, this study was financed in part by the Coordenação de Aperfeiçoamento de Pessoal de Nível Superior - Brasil (CAPES) - Finance Code 001

\section{Corresponding Author}

Vitor Ciampolini

Universidade Federal de Santa Catarina, Graduate Program in Physical Education

Campus Reitor João David Ferreira Lima, s/n Florianópolis 88040-900, Brazil

E-mail: vciampolini@gmail.com

Manuscript received on April 17, 2018

Manuscript accepetd on September 3, 2018

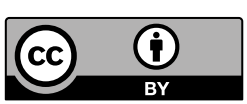

Motriz. The Journal of Physical Education. UNESP. Rio Claro, SP, Brazil - eISSN: 1980-6574 - under a license Creative Commons - Version 3.0 